\title{
Meningioma intramedular cervical: relato de caso e revisão da literatura
}

\author{
Ricardo Brandão Fonseca', Josildo Pereira Marins Filho², Gray \\ Portela ${ }^{3}$, Nilson Bandeira Castelo Branco ${ }^{4}$, Luciene Seixas ${ }^{4}$ \\ Hospital Geral e Urgência (HGU), Instituto Mente e Cérebro (IMC), Petrolina, PE, \\ Hospital São Rafael, Salvador, BA.
}

\section{RESUMO}

Os meningiomas estão entre os tumores benignos mais comuns do canal espinhal, em adultos, encontrados, predominantemente, nos segmentos torácicos. Segundo a literatura, a ocorrência de um meningioma intramedular cervical é muito rara, com apenas oito trabalhos científicos relatados até o momento. Apresentaremos o nono relato de caso - talvez o primeiro relato publicado na literatura médica brasileira - e revisaremos os estudos anteriores. Paciente, de 40 anos de idade, iniciou com sintomas de fraqueza na mão direita e dores cervicais que se agravavam durante a noite. A ressonância magnética revelou lesão intramedular extensa cervical. A paciente foi submetida somente à biópsia, por causa de dificuldades na ressecção, sendo depois proposta radioterapia. O tumor teve uma discreta redução, a paciente permaneceu sem piora dos sinais e sintomas durante os oito anos de evolução. Embora muito raros, meningiomas intramedulares cervicais existem e devem estar no diagnóstico diferencial de tumores nessa localização. O principal tratamento dessas lesões, de acordo com relatos anteriores, é a cirurgia, com bons resultados.

\section{PALAVRAS-CHAVE}

Meningioma/diagnóstico, meningioma/cirurgia, vértebras cervicais, neoplasias da medula espinal.

\begin{abstract}
Intramedullary cervical meningioma: a case report and literature review

Meningiomas are among the most common benign tumours of the spinal canal in adults, found predominantly in the thoracic segments. According to the literature, the occurrence of an intramedullary cervical meningioma is very rare, with only eight scientific papers reported in the literature so far. We present the ninth case report - probably the first reported in the Brazilian medical literature - and review the previous reports. 40-year-old patient, who started the symptoms with weakness in her right hand and neck pain that worsened at night. The MRI revealed extensive intramedullary cervical lesion. The patient underwent biopsy only and, then, underwent radiotherapy. The tumor had a slight reduction and the patient remained without worsening of signs and symptoms during the eight years of evolution. Although very rare, intramedullary cervical meningiomas should be in the differential diagnosis of tumors of this location. The main treatment of these lesions, according to previous reports, is surgery with excellent results.
\end{abstract}

\section{KEYWORDS}

Meningioma/diagnosis, meningioma/surgery, cervical vertebrae, spinal cord neoplasms.

\section{Introdução}

Meningiomas estão entre os tumores que mais acometem o canal espinal nos adultos. Cerca de $25 \%$ dos tumores do canal espinhal são meningiomas. Estima-se que $14 \%$ a $18,5 \%$ localizem-se na região cervical, $75 \%$ a $82 \%$, na região torácica e $2 \%$ a $7 \%$, na região lombar. ${ }^{4}$ São, na sua quase totalidade, extramedulares.
Os tumores intramedulares são mais raros, correspondem apenas a $5 \%$ dos tumores espinhais, sendo os astrocitomas e ependimomas reconhecidamente os mais frequentes nessa localização. ${ }^{1}$

$\mathrm{O}$ acometimento intramedular do meningioma existe e, em qualquer seguimento, é extremamente raro, sendo descrito na literatura somente como "relato de caso". Até o momento, encontramos cerca de oito

1. Sociedade Brasileira de Neurocirurgia, Hospital Geral e Urgência (HGU), Instituto Mente e Cérebro (IMC), Petrolina, PE.

2. Hospital São Rafael, Salvador, BA.

3. Universidade Federal do Vale do São Francisco (UNIVASF).

4. HGU, IMC. 
trabalhos sobre meningiomas intramedulares cervicais descritos na literatura, todos estrangeiros. ${ }^{1,2,5-10}$

O presente estudo visa, portanto, relatar mais um caso na literatura mundial - talvez o primeiro relato de caso brasileiro - e revisar os demais estudos sobre o assunto publicados até o momento.

\section{Caso clínico}

Paciente, sexo feminino, 40 anos, professora. Iniciou quadro em 2002, com queixa de fraqueza em membro superior direito, principalmente na mão - "Eu deixava as coisas caírem de minha mão e não percebia.” -, associado a desconforto (dor) em região cervical, que piorava à noite. $\mathrm{O}$ quadro de perda de força progrediu para os membros inferiores, com preservação das funções esfincterianas.

Seu exame neurológico mostrava uma quadriparesia grau IV (deambula sem ajuda), pior em seguimentos distais; reflexos tendinosos profundos exaltados em membros superiores, com predileção pelo dimídio direito; reflexos patelares simétricos, sem alterações; discreta amiotrofia em mãos, mais acentuada à direita; diminuição de sensibilidade vibratória, tátil e termoalgésica nos quatro membros.

A paciente foi submetida, em 2007, à investigação com RNM da coluna cervical (Figuras 1 A e B). que mostrou extensa lesão, intramedular, sem captação importante de contraste, que envolvia a transição bulbo-medular até, aproximadamente, o platô inferior de C4. Foi, então, submetida à cirurgia, na qual se identificou lesão bastante endurecida, muito aderida ao plano medular e de difícil ressecção, quando se optou apenas por biópsia. A biópsia revelou tumor compatível com meningioma meningoteliomatoso. $\mathrm{O}$ painel de imunomarcadores, composto por antígeno de membrana epitelial (E29), proteína ácida fibrilar glial (GFAP), proteína S-100 e vimentina filamento intermediário mesenquimal (V9), foi inconclusivo. O receptor de estrógeno (RE) 1D5 foi negativo.

Após discussão com o serviço de oncologia, optou-se por radioterapia, em 2008. O exame de controle revela discreta redução da lesão, bem como surgimento de áreas compatíveis com necrose intratumoral (Figura 2).

A paciente evolui sem nenhuma piora neurológica até a presente data, no acompanhamento ambulatorial, após um seguimento de quatro anos do diagnóstico e de oito anos do início dos primeiros sintomas.

\begin{tabular}{|c|c|c|c|c|c|c|}
\hline Referência/ano & Idade & Nível & Sexo & Subtipo & Tratamento & Resultado \\
\hline $\begin{array}{l}\text { Pansini e } \\
\text { Conti }^{7} / 1981\end{array}$ & $? / ?$ & $\begin{array}{l}\mathrm{C} 3 / \mathrm{C} 4 \\
\mathrm{C} 1 / \mathrm{C} 2\end{array}$ & $\mathrm{M} / \mathrm{M}$ & $\begin{array}{l}\text { Angioblástico } \\
\text { psamomatoso }\end{array}$ & Ressecção total & $\begin{array}{l}\text { Melhora neurológica } \\
\text { seguida de óbito por } \\
\text { complicações respiratórias }\end{array}$ \\
\hline Pagni $6 / 1989$ & ? & ? & $\mathrm{F}$ & Papilar & ? & ? \\
\hline Salvati et al. ${ }^{10} / 1992$ & 67 & $\mathrm{C} 2 / \mathrm{C} 4$ & $\mathrm{~F}$ & Fibroblástico & Ressecção total & Sem complicações \\
\hline $\begin{array}{l}\text { Moriuchi et } \\
\text { al. }{ }^{5} / 1996\end{array}$ & 54 anos & Medula oblonga até? & $\mathrm{F}$ & Transicional & ? & ? \\
\hline Jallo et al. ${ }^{2} / 2001$ & 22 meses & $\mathrm{C} 3 / \mathrm{C} 5$ & $\mathrm{~F}$ & Clear cells & $\begin{array}{l}\text { Duas ressecções } \\
\text { parciais seguidas de } \\
\text { ressecção radical } \\
+ \text { radioterapia }\end{array}$ & $\begin{array}{l}\text { Recorrências após ressecção } \\
\text { parcial. Sem recidiva local } \\
\text { após ressecção total. Metástase } \\
\text { para fossa posterior }\end{array}$ \\
\hline Covert et al..$^{1 / 2} 2003$ & ? & ? & ? & ? & $?$ & ? \\
\hline $\begin{array}{l}\text { Salehpour et } \\
\text { al. }{ }^{9} / 2008\end{array}$ & 22 anos & $\begin{array}{l}\text { Transição } \\
\text { cervicomedular } \\
\text { até C3 }\end{array}$ & M & Meningotelial & Ressecção parcial & $\begin{array}{l}\text { Sem progressão até } 3 \\
\text { anos de seguimento }\end{array}$ \\
\hline Sahni et al. ${ }^{8} / 2008$ & 42 & $\mathrm{C} 3$ até $\mathrm{T} 2$ & M & $\begin{array}{l}\text { Meningioma atípico } \\
\text { grau II (WHO), } \\
\text { "Exofítico" }\end{array}$ & Ressecção total & $\begin{array}{l}\text { Sem complicações e } \\
\text { com melhora clínica }\end{array}$ \\
\hline Fonseca et al./2011 & 41 & $\begin{array}{l}\text { Transição } \\
\text { cervicomedular } \\
\text { até C4 }\end{array}$ & $\mathrm{F}$ & Meningotelial & $\begin{array}{l}\text { Biópsia e } \\
\text { radioterapia }\end{array}$ & $\begin{array}{l}\text { Estabilidade clínica e não } \\
\text { progressão do tumor }\end{array}$ \\
\hline
\end{tabular}

M: masculino; F: feminino; WHO: World Health Organization. 


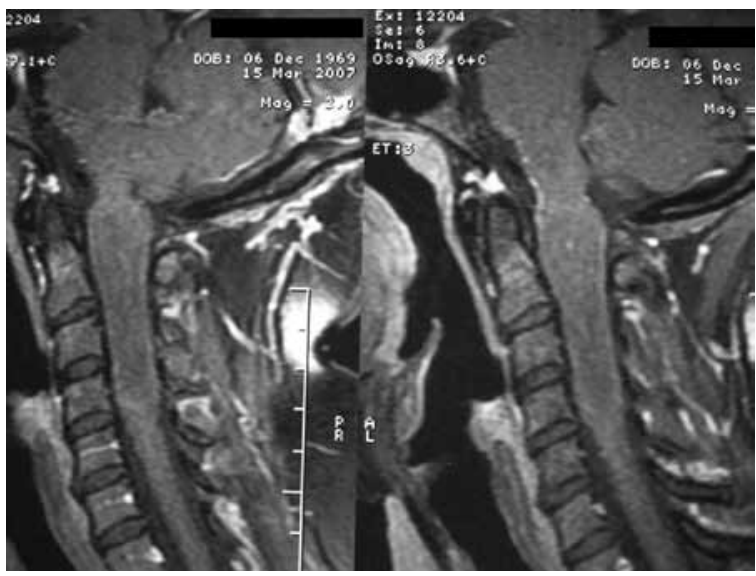

Figura 1A

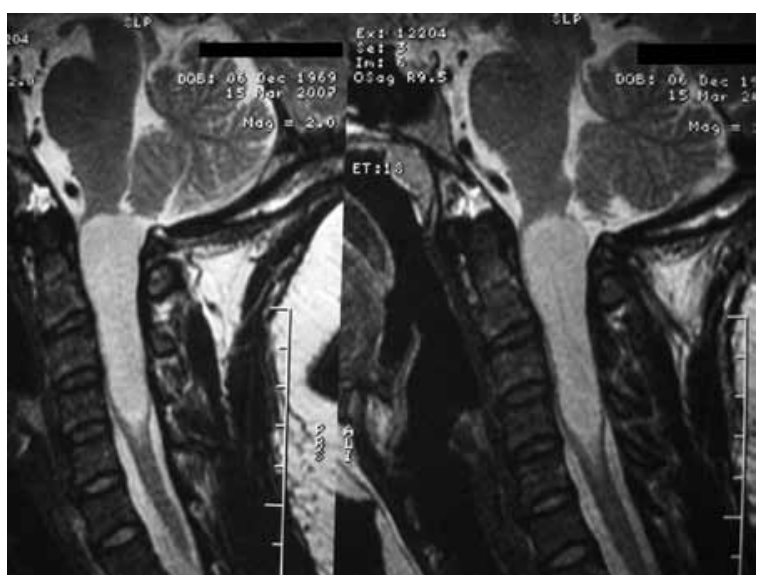

Figura 1B

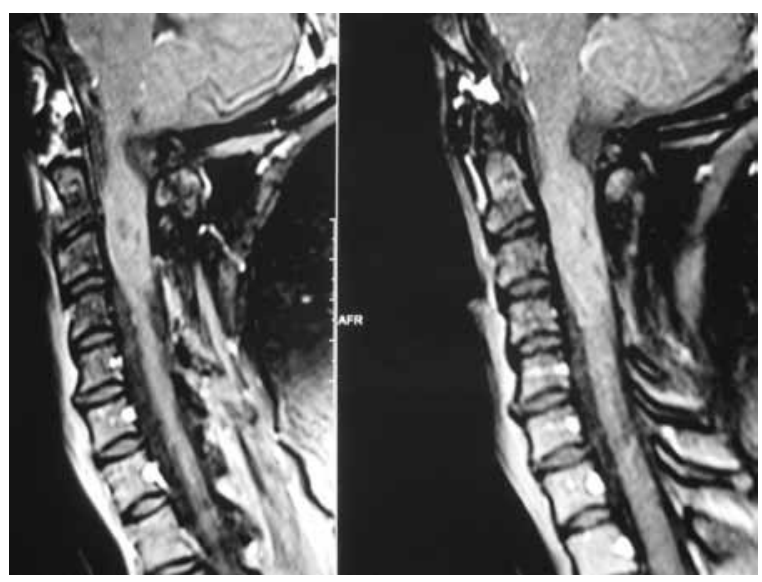

Figura 2

\section{Discussão}

Até a presente data, identificamos, na literatura médica, apenas oito trabalhos (Tabela 1) - todos relatos de casos - a respeito dos meningiomas intramedulares cervicais. A dificuldade em relação a encontrar estudos com maiores séries certamente está relacionada à raridade dessas lesões.

Após analisar os trabalhos anteriores, percebemos que os meningiomas intramedulares cervicais podem se apresentar nas mais diversas faixas etárias, variando de 22 meses de vida ${ }^{2}$ até 67 anos de idade, ${ }^{10}$ predominando, entretanto, nos adultos. Em relação à distribuição por sexo, nota-se distribuição, mais ou menos, igualitária entre homens e mulheres, o que os difere dos demais meningiomas, os quais acometem mais as mulheres. ${ }^{4}$

Mas o que chama atenção, particularmente nos casos desses meningiomas intramedulares, é sua topografia no canal espinhal. Observa-se uma clara tendência desses tumores de localizarem-se na região cervical, principalmente nos seguimentos mais altos, muitas vezes, inclusive, iniciando-se na região bulbo-medular. ${ }^{2,5,7-10}$ Os demais meningiomas espinhais, ao contrário, acometem, preferencialmente, a região torácica. ${ }^{3,4}$ Encontramos apenas um relato de meningioma intramedular torácio. ${ }^{3}$

No que diz respeito aos tipos histológicos, podem-se encontrar os tipos: meningotelial, fibroblástico, transicional, angioblástico, células claras, papilares, ${ }^{9}$ além dos atípicos. Este caso é o segundo descrito do tipo meningotelial, observando-se, nos demais casos descritos, uma divisão equitativa entre os diversos outros tipos.

Os meningiomas de células claras espinhais são raros. ${ }^{3}$ Nota-se, entretanto, que esse tipo - de maior agressividade - parece ter uma predileção, em termos proporcionais, para o acometimento espinhal, em especial no espaço intramedular. ${ }^{2,3}$ Segundo Kim et al. ${ }^{3}$, dos raros casos relatados de meningiomas intramedulares, dois são de células claras, sendo um torácico e outro cervical.

A base de tratamento para todos os casos foi a cirurgia com resultados satisfatórios. As cirurgias variavam de biópsia, seguida de radioterapia (presente caso), até cirurgias radicais, seguindo-se de radioterapia, no caso de lesão mais agressiva, conforme Jallo et al. ${ }^{2}$ No caso mostrado neste trabalho, procedeu-se apenas à biópsia, em virtude das dificuldades técnicas encontradas no intraoperatório. Apesar de ressecção insatisfatória, a paciente evolui bem, no seu seguimento de oito anos do início dos sintomas e quatro anos do tratamento, sem progressão do volume tumoral nem dos sinais e sintomas neurológicos, tendo sido apenas readaptada no seu trabalho. 
A patogênese dos meningiomas intramedulares permanece obscura. Shuangshoti et al. ${ }^{11}$ sugerem que esses tumores podem ser originários de células mesenquimais que revestem os espaços vasculares do neuroeixo.

Os meningiomas intramedulares são lesões extremamente raras, possuem predileção pela região cervical, nos seus seguimentos mais altos, e não têm características próprias de imagem que os diferenciem dos outros tipos mais comuns - astrocitomas e ependimomas.

Seu tratamento é cirúrgico, com bom prognóstico, dependendo do seu tipo histológico, sendo a radioterapia uma alternativa em alguns casos, como tratamento complementar. O seguimento, de perto, desses pacientes é fundamental.

Os meningiomas intramedulares devem ser lembrados nos diagnósticos diferenciais das lesões tumorais intramedulares, principalmente cervicais.

São necessários estudos maiores para melhor avaliação da história natural desses meningiomas, bem como forma mais adequada de tratamento para seus diferentes tipos histológicos.

\section{Referências}

1. Covert S, Gandhi D, Goyal M, Woulfe J, Belanger E, Miller $W$, et al. Magnetic resonance imaging of intramedullary meningioma of the spinal cord: case report and review of the literature. Can Assoc Radiol J. 2003;54(3):177-80.
2. Jallo GI, Kothbauer KF, Silvera VM, Epstein FJ. Intraspinal clear cell meningioma: diagnosis and management: report of two cases. Neurosurgery. 2001;48(1):218-21.

3. Kim MS, Park SH, Park YK. Thoracic intramedullay clear cell meningioma. J Korean Neurosurg Soc. 2006;39:389-93.

4. Levy WJ Jr, Bay J, Dohn D. Spinal cord meningioma. J Neurosurg. 1982;57(6):804-1.

5. Moriuchi S, Nakagawa H, Yamada M, Kadota T. Intramedullary spinal cord meningioma - a case report. Neurol Med Chir (Tokyo). 1996;36(12):888-92.

6. Pagni CD. I Meningiomi spinali. Roma: CIC Edizioni Internazionali; 1989.

7. Pansini A, Conti P. On some rare spreading cervical lesions. J Neurosurg Sci. 1981;25(3-4):255-7.

8. Sahni D, Harrop JS, Kalfas IH, Vaccaro AR, Weingarten D. Exophytic intramedullary meningioma of the cervical spinal cord. J Clin Neurosci. 2008;15(10):1176-9.

9. Salehpour F, Zeinali A, Vahedi P, Halimi M. A rare case of intramedullary cervical spinal cord meningioma and review of the literature. Spinal Cord. 2008;46(9):648-50.

10. Salvati M, Artico M, Lunardi P, Gagliardi FM. Intramedullary meningioma: case report and review of the literature. Surg Neurol. 1992;37(1):42-5.

11. Shuangshoti S, Netsky MG, Jane JA. Neoplasms of mixed mesenchymal and neuroepithelial type. With consideration of the relationship between meningioma and neurilemmoma. J Neurol Sci. 1971;14(3):277-91.

\section{Endereço para correspondência}

Ricardo Brandão Fonseca

Av. Cardoso de Sá, 13, ap. 802, Centro

56302110 - Petrolina, PE, Brasil

Telefones: (87) 8843-6199/(87) 9606-2010

E-mail: ricardoneurocirurgia@uol.com.br 